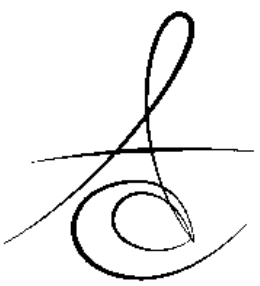

\title{
ZİRKONYA RESTORASYONLARDA RENKLENDİRME
}

\section{COLORING IN ZIRCONIA RESTORATIONS}

Dt. Ceyda Başak İNAL*

Doç. Dr. Merve BANKOĞLU GÜNGÖR*

Prof. Dr. Seçil KARAKOCA NEMLí*

Makale Kodu/Article code: 4396
Makale Gönderilme tarihi: 23.05 .2020
Kabul Tarihi: 05.11 .2020

DOI: $10.17567 /$ ataunidfd.822036
Ceyda Başak İnal: ORCID ID: 0000-0001-6573-7976

Merve Bankoğlu Güngör: ORCID ID: 0000-0002-4002-6390

Seçil Karakoca Nemli: ORCID ID: 0000-0001-8836-0673

\section{öz}

Günümüzde protetik tedavilerde tam seramik restorasyonların kullanımı oldukça yaygınlaşmıştır. Zirkonya yüksek mekanik dayanımı nedeniyle sıkıkla kullanılan bir tam seramik materyalidir. Opaklığı sebebiyle başlangıçta altyapı maddesi olarak kullanılmış ve cam seramikler ile veneerlenmiş ancak sıklıkla venner başarısızlıkları görülmüştür. Bu nedenle translusensi özelliği arttırılarak monolitik olarak kullanımı gündeme gelmiștir. Cam seramiklere göre yüksek opasiteye sahip olan zirkonyanın özellikle monolitik kullanımında ortaya çıkan estetik dezavantajlarını azaltmak ve doğal dişe yakın bir görünüm elde etmek için renklendirme işlemleri titizlikle yapılmalıdır. Bilgisayar destekli tasarım ve üretim teknikleriyle restorasyonların üretiminde kullanılan zirkonya bloklar, çoğunlukla yarı sinterize halde bulunmaktadır. Bu yöntemle renksiz ve kendinden renkli bloklardan restorasyonlar üretilebilirken; renksiz bloklardan üretilen restorasyonlar, sinterleme işlemi öncesinde solüsyonlar yardımıyla veya sinterleme işlemi sonrasında dış boyama ile renklendirilebilmektedir. Ancak uygulanan bu renklendirme işlemleri zirkonyanın özelliklerini etkileyebilmektedir. Literatürde zirkonyanın renklendirme yöntemleri ve renklendirmenin zirkonya üzerindeki etkileriyle ilgili birçok çalışma mevcuttur. Bu derleme makalesinde zirkonyanın renklendirme prosedürleri anlatılmış ve bu işlemlerin zirkonya üzerine olan etkilerinin değerlendirilmesi amaçlanmıştır.

Anahtar Kelimeler: Zirkonyum, renklendirme, dental porselen, yttria stabilize dörtgen zirkon

\section{ABSTRACT}

Nowadays, the use of all ceramic restorations in prosthetic treatments has gained popularity. Due to its high mechanical strength, zirconia is frequently used in all ceramic dental restorations. Zirconia was initially used as a core material in dental restorations which was veneered with a glass ceramic because of its opacity. However, the high frequency of veneer failures led the use of monolithic zirconia with increased tranlucency. To reduce the esthetic disadvantages of zirconia associated with its high opacity and to obtain a natural appearance, various coloring procedures especially for monolithic zirconia should be applied meticulously. In general, semi-sintered zirconia blocks are used in the production of dental restorations with computer aided design and manufacturing techniques. These blocks can be in the form of white color or industrially precolored. Restorations milled from white color blocks are colored with solutions prior to sintering or are stained after sintering. However, these coloring procedures could have some effects on the material properties as shown in the literature on coloring methods and their effects on zirconia. The aim of this review article is to reveal the coloring procedures of zirconia and to evaluate the effects of coloring processes on the material properties.

Keywords: Zirconium, coloring, dental porcelain, yttria stabilized tetragonal zirconia

\section{* Gazi Üniversitesi, Diş Hekimliği Fakültesi, Protetik Diş Tedavisi AD, Ankara}

Kaynakça Bilgisi: İnal CB, Bankoğlu Güngör M, Karakoca Nemli S. Zirkonya restorasyonlarda renklendirme. Atatürk Üniv Diş Hek Fak Derg 2021; 31: 662-8. Citation Information: Inal CB, Bankoglu Gungor M, Karakoca Nemli S. Coloring in zirconia restorations. J Dent Fac Atatürk Uni 2021; 31: 662-8.

\section{GİRİŞ}

Diş hekimliğinde estetik beklentilerdeki ve teknolojik gelişmelerdeki artış tam seramiklerin kullanımını yaygınlaştırmıştır. Zirkonya, 1990'ların başında diş hekimliğinde kullanılmaya başlanmıştır. ${ }^{1}$ Başlangıçta endodontik postlarda, implantların üst yapılarında ve ortodontik braketlerde kullanilırken, zamanla tam seramik restorasyonlarda alternatif bir altyapı maddesi olmuştur. $^{2-4}$ Son zamanlarda ise kron köprü protezlerinin yapımında monolitik olarak (tek tabakalı, veneerlenmeden) kullanımı gündeme gelmiştir. 
Zirkonya; yüksek biyouyumluluk, gelişmiş estetik ve yüksek dayanıklıık gibi özellikleriyle kron ve köprü protezlerinin üretiminde yaygın olarak kullanılmaktadır. ${ }^{1,5}$ Tek kronların ve sabit bölümlü protezlerin yapımında tabakalı (veneer uygulanan) ve monolitik (anatomik konturlu) olmak üzere iki tip zirkonya restorasyon kullanılmaktadır. Zirkonya yüksek opaklık gösteren bir madde olduğu için başlangıçta altyapı maddesi olarak kullanılmış ve cam seramiklerle veneerlenmiştir. Ancak kanıta dayalı klinik bulgular; veneerlenmiş zirkonya kronlarda başarısızlığın \%74-100 gibi yüksek oranlarda görüldüğünü ve başarısızlıkların büyük bir kısmının, veneer porseleninde atma (chipping) veya kırılmadan oluştuğunu ortaya koymuştur. ${ }^{6}$ Veneer porseleni ve zirkonya altyapı arasında ısısal genleşme katsayısı uyumsuzluğundan kaynaklanan residüel stresler, düşük altyapı-veneer bağlantı kuvveti ve veneer tabakasını uygun şekilde desteklemeyen zirkonya altyapı tasarımlarının veneer porseleninde başarısızlığa yol açan önemli nedenler olduğunu göstermektedir. ${ }^{7-10} \mathrm{Bu}$ problemin üstesinden gelebilmek amacıyla; zirkonya altyapılar için geliştirilmiş veneerleme yöntemleri ${ }^{11-14}$ ve veneer tabakanın tamamen ortadan kaldırıldığı monolitik zirkonya restorasyonların kullanılması ${ }^{7,15}$ olmak üzere iki farklı yaklaşım geliştirilmiştir.

Monolitik zirkonya restorasyonların, düşük kalınIıkta bile yüksek mekanik dayanım göstermeleri, kabul edilebilir estetik sonuçları, tabakalı restorasyonlara göre kısa üretim süresi ve maliyetin azalması gibi olumlu özellikleri ile kısa sürede kullanımları yaygınlaşmıştır. ${ }^{16}$ Ancak monolitik zirkonya restorasyonlar, cam seramikler ile veneerlenen zirkonya restorasyonlara göre daha yüksek opaklık göstermeleri sebebiyle ön bölge restorasyonlarında estetik beklentileri karşılayamamakta ve daha çok posterior bölgede tercih edilmektedir. ${ }^{7}$ Son yıllarda ise monolitik kullanıma uygun zirkonyanın daha da arttırılmış translusensi özelliği ve farklı estetik gereksinimleri karşılayabilecek renklendirme teknolojileri sayesinde kullanım alanları artmaktadır. $^{5}$

\section{Zirkonya Restorasyonlarda Renklendirme}

Seramik restorasyonların ağız içindeki görünümü; seramiğin rengi, translusensi özelliği, kalınlığı, kullanılan simanın rengi ve destek diş rengi başta olmak üzere çeşitli etkenlere bağlıdır. ${ }^{17,18}$ Doğal görünümlü seramik restorasyonlar elde edebilmek için tüm bu etkenlerin göz önünde bulundurulması gerekiyorsa da doğru seramik renginin seçimi ve uygun renklendirme işlemlerinin yapılması en kritik aşamadır.
Monolitik zirkonya restorasyonlarda renk açısından iyi bir estetik sağlamak, doğal dişlerin katmanlı yapısı ve bölgesel olarak değişen renkleri göz önüne alındığında zor olabilmektedir. İlk kullanıma sunulan monolitik zirkonya restorasyonlar genellikle renklendirme yapılmamış, beyaz yarı sinterize bloklardan üretilmiştir. Günümüzde, üretici firmalar tarafından farklı renk seçeneklerine sahip olarak üretilen monolitik zirkonya blokların yanı sıra çok tabakalı veya renk geçişli zirkonya bloklar da mevcuttur. ${ }^{19}$

Zirkonyanın restorasyonun renklendirmesi üretiminin farklı aşamalarında yapılabilmektedir:

a. Renklendirilme yapılmamış, beyaz yarı sinterize bloklardan restorasyon şekillendirildikten sonra sinterizasyon öncesi renklendirme

b. Üretici firma tarafından farklı diş renklerinde üretilmiş bloklardan restorasyonun şekillendirilmesi

c. Sinterizasyon sonrası renklendirme

\section{a. Renklendirilme yapılmamıs yarı sinterize bloklardan şekillendirilen restorasyonun sinterizasyon öncesi renklendirilmesi}

Zirkonya restorasyonlar renklendirilmemiş yarı sinterize bloklardan şekillendirildikten sonra sinterizasyon öncesinde renklendirici solüsyona daldırılarak (infiltrasyon) veya renklendirici solüsyonun fırça ile uygulanmasıyla renklendirilebilmektedir. ${ }^{5}$ Ancak zirkonyanın solüsyonlar ile renklendirilmesi bazı olumsuzlukları beraberinde getiren bir tekniktir. Buna göre; solüsyonda bekleme ilave zaman gerektiren hassas bir işlemdir, uygulamayı yapan kişinin hatalarına açıktır. Elde edilen restorasyon rengi homojen olmayabilir ve solüsyon içeriğindeki renklendirici iyonlar yüzeyden belirli bir derinliğe kadar nüfuz edebilir. Ayrıca solüsyonların raf ömrü kısa olup içeriğindeki renklendirici pigmentlerin zamanla buharlaşması veya çökelmesi sonucu renklendirme özelliği değişebilir. ${ }^{20}$ Aynı zamanda renklendirici solüsyonlar, zirkonyanın mekanik özelliklerini etkileyebilecek kristal ve mikroyapısal değişikliklere yol açma eğilimine sahip metal oksitler içerir. ${ }^{15,21}$

Yarı sinterize haldeki zirkonya restorasyonları renklendirmede kullanılan solüsyonların, "asidik renklendirici solüsyonlar" ve asit bileşeni içermeyen "su bazlı renklendirici solüsyonlar" olmak üzere iki farklı türü bulunmaktadır. ${ }^{7,22}$ Asit içerikli renklendirici solüsyonlar kütlece \%0,1 HCI (pH 1-3) gibi güçlü bir asit içerir. Bu asidik solüsyon sayesinde sadece asit içinde çözünebilir bazı metal tuzları renklendirmede kullanılır. Su bazlı renklendirme solüsyonları ise asitli bileşenler içermez ve metal katyonları gözenekli zirkonya altyapılarında filtreleyerek renk verir. Su bazlı renklendirme 
solüsyonlarında kullanılan nadir toprak metal iyonlarının uzun süreli renk stabilitesine sahip olduğu bilinmektedir. ${ }^{7}$ Ayrıca uygulama ve sinterleme işlemleri sırasında asitli duman yayılması söz konusu olduğu için su bazlı renklendirme solüsyonları laboratuvar personeli için de daha güvenlidir. Bu nedenlerle, yarı siterize zirkonyanın renklendirilmesinde su bazlı solüsyonların asit içerikli olanlardan daha iyi bir seçenek olduğu düşünülmektedir. ${ }^{7}$

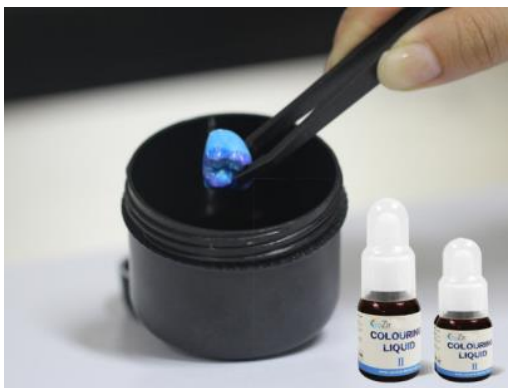

Resim 1. Renklendirici solüsyona daldırılarak renklendirme ${ }^{26}$

Renklendirici solüsyon ile sinterizasyon öncesinde renklendirmede kullanılan diğer bir yöntem, solüsyonların restorasyon yüzeyine fırça ile uygulanmasıdır. Bu yöntem, solüsyona daldırma ile karşılaştırıldığında, birden fazla rengin bölgesel olarak uygulamasına izin vermesi avantajına sahiptir. ${ }^{15}$ Ancak fırça ile renklendirme, uygulayanın becerisi ve tecrübesine bağlı bir işlem olduğu için doğru uygulaması infiltrasyon tekniğine göre daha zordur. Yapılan çalışmalar infiltrasyon tekniğinin doğru uygulandığında doğal diş renklerinin sağlanmasında daha başarılı sonuçlar verdiğini ortaya koymuştur. 23,24,25

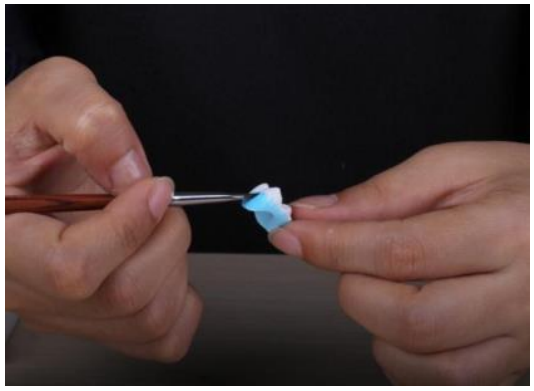

Resim 2. Renklendirici solüsyonun fırça ile uygulanması ile renklendirme ${ }^{27}$

\section{b. Üretici firma tarafından farklı diş renklerinde blok üretimi}

Zirkonya restorasyonlar için son yıllarda birçok firma dişlerin farklı renk tonlarını taklit eden renklendirilmiş yarı sinterize blokları kullanıma sunmuştur. Bu bloklar; zirkonya tozunun blok haline getirilmesi esnasında yapıya metal oksitler eklemesi yoluyla elde edilir ve bu üretim yöntemine "ilave teknik" adı verilir.,22 $\mathrm{Bu}$ bloklardan üretilen restorasyonlar solüsyonda bekletme yöntemi ile renklendirilen restorasyonlara göre; tüm kitle boyunca homojen dağımış renklendiriciler içermesi, fiziksel ve mekanik özelliklerini etkileyebilen renklendirme işlemlerini gerektirmemesi ve kullanıcıya bağlı hatalar sebebiyle hedeflenenden farklı renk tonları elde etme riskinin olmaması gibi avantajlara sahiptir. ${ }^{15,28}$

Son dönemde, renklendirilmiş zirkonya bloklar doğal dişlerin renk geçişlerini taklit edebilen çok katmanlı veya renk geçişli olarak hazırlanmaktadır. Bu bloklar, mine ve dentinin translusensi ve renk özelliklerini taklit eden renk katmanlarına sahiptir. Çok katmanlı zirkonya blokların üretimi 2 farklı teknikle yapılmaktadır. Bunlardan biri infiltrasyon tekniği olarak adlandırılıp, parlaklığı ve doygunluğu birbirinden farklı renklendirme solüsyonlarının bloğun istenen bölgelerine uygulanmasını içerir. Diğer teknikte ise bloğun farklı tabakalarında zirkonya partikül boyutları değiştirilerek ışık absorbsiyon miktarı ayarlanır. ${ }^{22}$ Çok katmanlı zirkonya bloklar üç veya dört tabakaya sahip olabilir (örneğin; \% 35'i mine tabakası, \% 15'i ilk geçiş tabakası, \% 15'i ikinci geçiş tabakası ve \% 35'i dentin tabakası). Günümüzde farklı itriyum konsantrasyonlarına (\% 3-8 mol) sahip Y-TZP tozları ile yüksek mekanik dayanım sağlayan tetragonal fazdan translusensi sağlayan kübik faza kadar değişik fazlar içeren çok katmanlı bloklar üretilmektedir. ${ }^{29}$

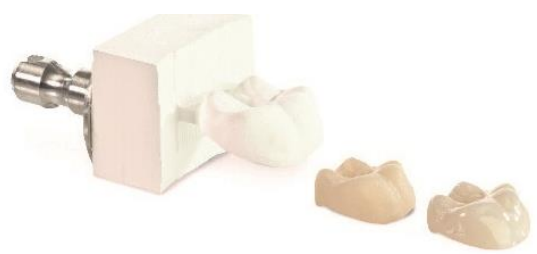

Resim 3. Kendinden renkli zirkonya blok ${ }^{30}$ (Sinterizasyondan sonra olması gereken renge ulaşır.)

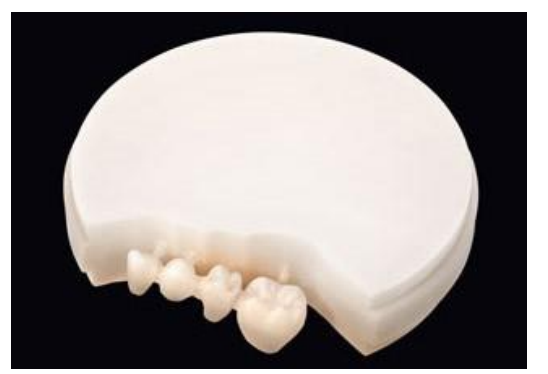

Resim 4. Çok katmanlı renk geçişli zirkonya ${ }^{31}$ 


\section{c. Sinterizasyon sonrası renklendirme}

Zirkonya ile doğal görünümlü restorasyonlar elde edebilmek için renklendirilmiş blokların kullanımı ve sinterizasyon işlemi öncesi renklendirme teknikleri daha elverişlidir. Ancak sinterleme sonrasında zirkonya yüzeyine uygulanan renklendirme teknikleri de mevcuttur ve intiyaç duyulabilmektedir. Sinterizasyonu yapılmış zirkonya altyapıların üzerine uygulanan bir astar tabakası, veneer porseleni altında istenen altyapı rengini sağlamaya yardımcı olmaktadır. Ancak astar maddelerinin, altyapı ile veneer seramiği arasındaki bağlantı üzerine olumsuz etkileri olabileceği bildirilmiştir. ${ }^{5,15}$

Monolitik zirkonya restorasyonlarda doğal dişlerle renk uyumu ancak sinterizasyon sonrası değerlendirilebilmektedir. Doğal dişlerle renk uyumu istenen şekilde elde edilememiş veya hedeflenen renge ulaşılamamış olduğu durumlarda restorasyon yüzeyinde uygun renklendiriciler ile boyama yapılabilmektedir. Ancak hem renklendirme hem de glaze işlemleri için yapılan ilave fırınlamalar; restorasyonun yapım süresini uzatma, laboratuvar seanslarını arttırma ve mekanik ve optik özelliklerini etkileme riski gibi olumsuzlukları beraberinde getirmektedir. ${ }^{29}$

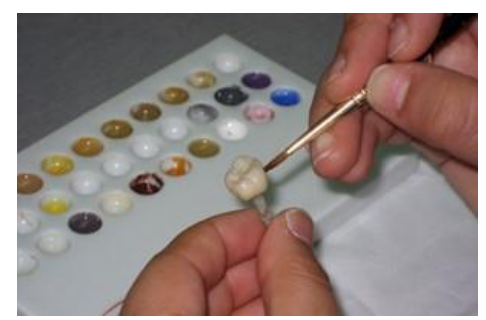

Resim 5. Sinterizasyon sonrası dış boyama ile renklendirme ${ }^{32}$

\section{Renklendirme İşlemlerinin Zirkonyanın Özellikleri Üzerine Etkileri}

Üretim aşamasında renklendirilmiş zirkonya bloklar günümüzde yaygın olarak kullanıımasına rağmen renklendirme solüsyonları ile yapılan renklendirme (infiltrasyon tekniği) halen birçok klinik durumda gerekli olmaktadır. Bu sebeple işlemin, zirkonyanın mekanik, optik ve yüzey özellikleri üzerine olan etkileri birçok araştırmacı tarafından incelenmiştir.

\section{2.a. Renklendirme İşlemlerinin Zirkonyanın Mekanik Özellikleri Üzerine Etkileri}

Yarı sinterize zirkonyanın infiltrasyon yöntemiyle renklendirme işlemi mekanik özelliklerini etkileyebilmektedir. Bu etkiler; solüsyonunun tipi, renk tonu, uygulanma sayısı ve solüsyonda bekletme süresine göre değişkenlik göstermektedir. Renklendiricilerin zirkonya seramiklerinin bükülme dayanımı ve kırıma tokluğu gibi mekanik özelliklerini olumsuz etkilediğini ortaya koyan birçok çalışma mevcuttur. 5,22,33

Renklendirme işlemine ait özelliklerin, zirkonya restorasyonların mekanik özellikleri üzerine etkilerini inceleyen çalışmalar; koyu renk tonları elde etmek için kullanılan renklendirme solüsyonlarının açık tonlara göre zirkonyanın mekanik dayanımını daha fazla azalttığını ortaya koymuştur. ${ }^{5,22,34}$ Zirkonyanın mekanik özelliklerini etkileyen diğer bir etkenin renklendirici solüsyon konsantrasyonu olduğu ve solüsyondaki renklendirici konsantrasyonu arttıkça, zirkonyanın bükülme dayanımının azaldığı bildirilmiştir. ${ }^{33,35}$ Solüsyonla renklendirme sırasında kullanılan asidik içerikli renklendirme solüsyonları, su bazlı solüsyonlara göre zirkonyanın yüzey sertliğini önemli ölçüde azaltmaktadır. ${ }^{7}$

Renklendirme solüsyonunda bekletme süresinin etkisini inceleyen çalş̧malar ise solüsyonda bekletme süresi uzadıkça (3- 60 sn.), zirkonyanın biaksiyel bükülme dayanımının, kırılma tokluğunun ve yüzey mikro-sertliğinin genellikle azaldığını ortaya koymuştur. ${ }^{34,36}$ Bu bulgulara karşın renklendirme solüsyonlarının zirkonyanın mekanik dayanımı üzerine önemli etkilerinin olmadığını savunan çalışmalar da mevcuttur. 22,35,37 Kuroda ve ark. ${ }^{38}$ solüsyonlarla renklendirme işlemi sonrası zirkonyanın eğilme direncinin en fazla \% 34 ve kırılma tokluğunun da en fazla \% 8 azaldığını belirtmiştir. Ek olarak renklendirici ajanların zirkonyanın mekanik özellikleri üzerindeki etkisinin bu ölçüde sorun yaratmasının olası olmadığını vurgulamışıı. Başka bir çalışmada ise, renklendirme işleminin kısa dönemde biaksiyel bükülme dayanımına etkisi olmadığı ancak uzun dönemde mekanik özelliklerini olumsuz etkilediği sonucuna varılmışır. ${ }^{39}$

\section{2.b. Renklendirme İşlemlerinin Zirkonyanın Bağlanma Özellikleri Üzerine Etkileri}

Sabit dental restorasyonlarda kullanılan zirkonyanın bağlanma özellikleri; simana bağlanma ve zirkonya altyapının veneer seramiğine bağlanması olmak üzere iki yönde incelenmektedir. Tam seramik restorasyonlarda altyapı olarak kullanılan zirkonyanın solüsyonla renklendirmesinin veneer seramik ile bağlantı dayanımını azalttığı ancak bu etkinin renk tonlarına göre değişkenlik gösterebileceği bildirilmiştir. ${ }^{36,40}$

Zirkonya restorasyonların diş dokusuna tutunması ve marjinal kapamanın sağlanması için geleneksel simanlar ve rezin simanlar kullanımaktadır. Rezin simanların zirkonya yüzeyine bağlantısının renklendir-

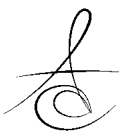


me işlemlerinden etkilendiği gösterilmiştir. ${ }^{41}$ Renklendirme solüsyonlarının zirkonya ve rezin arasındaki mikro-çekme bağlantı dayanımını değerlendiren bir çaışma ${ }^{42}$, farklı renk tonlarındaki solüsyonların bağlantıyı değişik şekilde etkilediğini bildirmiştir. Rezin siman ve zirkonya bağlantısının renklendirme işleminden etkilenmesinin, zirkonya yapısına infiltre olan renk verici bileşenlerin zirkonya yüzeyinin mikroyapısında meydana getirdiği değişikliklerden kaynaklı olabileceği düşünülmektedir. ${ }^{42}$

\section{2.c. Renklendirme İşlemlerinin Zirkonyanın Optik Özellikleri Üzerine Etkileri}

Zirkonyanın renklendirme solüsyonları ile renklendirilmesi, kristalografik ve mikroyapısal değişikliklere yol açmaktadır. 33,43 Solüsyonların içerdiği iyon ve metal oksitlerin türü ve bunların konsantrasyonu, solüsyonun uygulama tekniği ve süresi restorasyonun optik özelliklerini etkilemektedir. ${ }^{15,44,45,46} \mathrm{Bu}$ sebeple zirkonyanın renklendirilmesinde üretici önerileri titizlikle takip edilmelidir.

Zirkonya için translusensi yani ışık geçirgenliği; maddenin kimyasal yapısı, saflığı, tanecik büyüklüğü, sinterleme süresi ve sıcaklığı, iç yapısındaki porozite, kalınlığı ve simantasyon gibi çeşitli değişkenler tarafından etkilenebilen bir özelliktir. ${ }^{47,48}$ Birçok etken tarafından değiştirilebilen translusensi özelliğinin zirkonyanın renklendirme işlemlerinden kolayca etkilenmediği bildirilmiştir. ${ }^{43,49,50}$ Buna karşın benzer tanecik boyutlarına sahip renklendirilmiş ve renklendirilmemiş zirkonya karşılaştırıldığında renklendirmenin translusensiyi azalttığını ortaya koyan çalışmalar da mevcuttur. ${ }^{51,52}$ Renklendirme işleminin translusensiyi etkilememesi için solüsyonun renklendirici içeriğinin belirli sınırlar içinde ayarlanmış olması ve solüsyonda bekletme süresinin aşılmaması tavsiye edilebilir. ${ }^{53-55}$

\section{SONUÇ}

Zirkonya restorasyonlar, doğal dişe benzer estetik özelliklere sahip olabilmeleri için çeşitli yöntemlerle renklendirilmektedir. Zirkonyanın solüsyonlarla renklendirme işlemi ise restorasyon üretiminde ilave zaman ve aşama gerektiren, uygulamaya bağlı hataların meydana gelebildiği, homojen olmayabilen ve yüzeyden belirli bir derinliğe kadar nüfuz edebilen bir renklendirme sağlar. Bu sebeple üretim aşamasında renklendirilmiş zirkonya blokların kullanımı; yapım aşamaları kısaltılmış, homojen renklere sahip, fiziksel ve mekanik özellikleri optimum restorasyonlar sağlama avantajı sunar. Ancak blok renklerinin doğal dişlerin bölgesel ve tabakalı renklerini taklit edebilmesi için ilave renklendirme işlemleri gerekebilir. Sinterize olmuş zirkonya restorasyonların yüzeyine uygulanan renklendirme işlemi ise sadece diş yüzeyindeki yüzeysel renklenme ve renk efektlerinin sağlanmasında yararlı olmaktadır.

Zirkonya restorasyonlar ile doğal bir dişin rengini taklit edebilmek için kullanılan renklendirme yöntemlerinden herhangi birinin diğerlerine üstünlüğü kanıtlanmamıştır. Zirkonya teknolojisindeki gelişmelerle günümüzde uygun materyal seçimi ve doğru yöntemin uygulanmasıyla iyi bir renk uyumuna sahip estetik restorasyonlar elde edilebilmektedir.

Bu çalışma, çalışmayı yürüten tüm yazarlar tarafindan okunmuş ve onaylanmış orijinal bir çalışmadır. Herhangi bir yazar, kurum ya da kuruluş ile çıkar çatışması olmadığını belirtilmek isteriz.

\section{KAYNAKLAR}

1. El-Ghany OSA, Sherief AH. Zirconia based ceramics, some clinical and biological aspects. Futur Dent J 2016;2:55-64.

2. Stawarczyk B, Keul C, Eichberger M, Figge D, Edelhoff $D$, Lümkemann N. Three generations of zirconia: From veneered to monolithic. Part I. Quintessence Int 2017;48:369-80.

3. Bergmann C, Stumpf A. Ceramic Materials for Orthodontic Use. Dental Ceramics Microstructure, Properties, and Degradation. Springer: 2013. p.23,24.

4. Karakoca S, Yılmaz H. Zirkonyum ve sabit protezlerde kullanımı. Atatürk Üniv Diş Hek Fak Derg 2006;36-44.

5. Kim H-K, Kim S-H. Optical properties of precolored dental monolithic zirconia ceramics. J Dent 2016;55:75-81.

6. Roumanas ED. The clinical reliability of zirconiabased fixed dental prostheses appears acceptable but further research is necessary. J Evid Based Dent Pract 2013;13:14-5.

7. Nam J-Y, Park M-G. Effects of aqueous and acidbased coloring liquids on the hardness of zirconia restorations. J Prosthet Dent 2017;117:662-8.

8. Miyazaki $T$, Nakamura $T$, Matsumura $H$, Ban $S$, Kobayashi T. Current status of zirconia restoration. J Prosthodont Res 2013;57:236-61.

9. Al-Amleh B, Lyons K, Swain M. Clinical trials in zirconia: a systematic review. J Oral Rehabil 2010;37:641-52. 
10. Güngör MB, Nemli SK. Fracture resistance of CADCAM monolithic ceramic and veneered zirconia molar crowns after aging in a mastication simulator. J Prosthet Dent 2018;119:473-80.

11. Ferrari M, Giovannetti A, Carrabba M, Bonadeo G, Rengo $C$, Monticelli $F$, Vichi A. Fracture resistance of three porcelain-layered CAD/CAM zirconia frame designs. Dent Mater 2014;30:163-68.

12. Schmitter M, Schweiger M, Mueller D, Rues S. Effect on in vitro fracture resistance of the technique used to attach lithium disilicate ceramic veneer to zirconia frameworks. Dent Mater 2014;30:122-30.

13. Basso G, Moraes R, Borba M, Griggs J, Della Bona A. Flexural strength and reliability of monolithic and trilayer ceramic structures obtained by the CAD-on technique. Dent Mater 2015;31:1453-59.

14. Özcan M, Jonasch M. Effect of cyclic fatigue tests on aging and their translational implications for survival of all-ceramic tooth-borne single crowns and fixed dental prostheses. J Prosthodont 2018;27:364-75.

15. Sulaiman TA, Abdulmajeed AA, Donovan TE, Vallittu PK, Närhi TO, Lassila LV. The effect of staining and vacuum sintering on optical and mechanical properties of partially and fully stabilized monolithic zirconia. Dent Mater J 2015;34:605-10.

16. Sen N, Sermet IB, Cinar S. Effect of coloring and sintering on the translucency and biaxial strength of monolithic zirconia. J Prosthet Dent 2018; 119:308. e1-e7.

17. Kim H-K, Kim S-H, Lee J-B, Han J-S, Yeo I-S, Ha S$R$. Effect of the amount of thickness reduction on color and translucency of dental monolithic zirconia ceramics. J Adv Prosthodont 2016;8:37-42.

18. Alghazzawi TF. The effect of extended aging on the optical properties of different zirconia materials. J Prosthodont Res 2017;61:305-14.

19. Kolakarnprasert N, Kaizer MR, Kim DK, Zhang Y. New multi-layered zirconias: Composition, microstructure and translucency. Dent Mater 2019;35:797-806.

20. Kaya G. Production and characterization of selfcolored dental zirconia blocks. Ceram Int 2013;39:511-7.

21. Ban S, Suzuki T, Yoshihara K, Sasaki K, Kawai T, Kono $H$. Effect of coloring on mechanical properties of dental zirconia. J Med Biol Eng 2014; 34:24-9.
22. Yu N-K, Park M-G. Effect of different coloring liquids on the flexural strength of multilayered zirconia. J Adv Prosthodont 2019;11:209-14.

23. Mahmood DJH, Braian M, Khan A-S, Shabaz A, Larsson $C$. Fracture load of colored and noncolored high translucent zirconia three-unit fixed dental prosthesis frameworks. Acta Biomater Odontol Scand 2018;4:38-43.

24. Ahangari AH, Ardakani KT, Mahdavi F, Ardakani MT. The effect of two shading techniques on value of zirconia-based crowns. J Dent 2015;16:129.

25. Auzani ML, Dapieve KS, Zucuni CP, Pereira GKR, Valandro LF. Influence of shading technique on mechanical fatigue performance and optical properties of a 4Y-TZP ceramic for monolithic restorations. J Mech Behav Biomed Mater 2020;102:103457.

26. https://www.axsysdental.com/noc/axzir-dentalzirconia-shading-liquids.

27. http://www.dentalzirconiablank.com/sale-7615360gingival-zirconia-coloring-liquid-3-bottle-for-dyeingstaning-zirconia.html.

28. Rafael CF, Cesar PF, Fredel M, de Souza Magini R, Liebermann A, Volpato CAM. Impact of laboratory treatment with coloring and fluorescent liquids on the optical properties of zirconia before and after accelerated aging. J Prosthet Dent 2018;120:27681.

29. Tabatabaian F. Color aspect of monolithic zirconia restorations: a review of the literature. J Prosthodont 2018;28:276-87.

30. https://Imtmag.com/products/incoris-tm-tzi.

31.https://www.kulzer.com/int2/int/dental_technician/ products_a_to_z/dima_3/dima_mill_zirconia_ml.as px.

32https://www.protecdental.com/product/bruxzirrestorations.

33. Shah K, Holloway J, Denry I. Effect of coloring with various metal oxides on the microstructure, color, and flexural strength of 3Y-TZP. J Biomed Mater Res B Appl Biomater 2008;87:329-37.

34. Hjerppe J, Närhi T, Fröberg K, Vallittu PK, Lassila LV. Effect of shading the zirconia framework on biaxial strength and surface microhardness. Acta Odontol Scand 2008;66:262-7.

35. Sedda M, Vichi A, Carrabba M, Capperucci A, Louca $C$, Ferrari $M$. Influence of coloring procedure on flexural resistance of zirconia blocks. J Prosthet Dent 2015;114:98-102. 
36. Tuncel İ, Özat P, Eroğlu E. Effects of coloring procedures on zirconia/veneer ceramics bond strength. J Adv Prosthodont 2014;6:451-5.

37. Kong $M$, Kim K, Kown T, Hong M. The effects of the number of times dipped in coloring liquid and final sintering temperature on flexural strength of zirconia ceramics: Zirconia ceramics having improved transparency. Kor J Dent Mater 2017;44:171-8.

38. Kuroda S, Shinya A, Yokoyama D, Gomi H, Shinya A. Effects of coloring agents applied during sintering on bending strength and hardness of zirconia ceramics. Dent Mater J 2013;32:793-800.

39. Tuncel I, Turp I, Usumez A. Effect of color shading procedures and cyclic loading on the biaxial flexural strength of zirconia. Niger J Clin Pract 2018;21:7-12.

40. Celik S, Ucar Y, Ekren O. Effect of coloring liquids on color of zirconia frameworks and bond strength of zirconia/veneering ceramic. J Prosthet Dent 2020;124:110-5.

41. Berijani N, Mahshid M, Tabatabaian F, Sadr SJ. Dipping impact on the bond strength between zirconia ceramic and a resin cement. Regen Reconstr Restor 2017;2:44-9.

42. Mahshid M, Berijani N, Sadr SJ, Tabatabaian F, Homayoon SS. Effect of coloring-by-dipping on microtensile bond strength of zirconia to resin cement. J Dent 2015;12:414-23.

43. Pekkan G, Özcan M, Subaşı MG. Clinical factors affecting the translucency of monolithic Y-TZP ceramics. Odontology 2019, DOI: 10.1007/s10266019-00446-2.

44. Orhun E. The effect of coloring liquid dipping time on the fracture load and color of zirconia ceramics. J Adv Prosthodont 2017;9:67-73.

45. Kim H-K, Kim S-H. Effect of the number of coloring liquid applications on the optical properties of monolithic zirconia. Dent Mater 2014;30:229-37.

46. Giti R, Hojati SA. Effect of varying thickness and number of coloring liquid applications on the color of anatomic contour monolithic zirconia ceramics. J Dent 2018;19:311-9.

47. Abdelbary $O$, Wahsh $M$, Sherif $A$, Salah T. Effect of accelerated aging on translucency of monolithic zirconia. Futur Dent J 2016;2:65-69.

48. Sen N, Isler S. Microstructural, physical, and optical characterization of high-translucency zirconia ceramics. J Prosthet Dent 2019;123:761-8.
49. Kim H-K, Kim S-H, Lee J-B, Ha S-R. Effects of surface treatments on the translucency, opalescence, and surface texture of dental monolithic zirconia ceramics. J Prosthet Dent 2016;115:773-9.

50. Zhang Y. Making yttria-stabilized tetragonal zirconia translucent. Dent Mater 2014;30:1195203.

51. Tuncel İ, Turp I, Üşümez A. Evaluation of translucency of monolithic zirconia and framework zirconia materials. J Adv Prosthodont 2016;8:1816.

52. Tuncel I, Eroglu E, Sari T, Usumez A. The effect of coloring liquids on the translucency of zirconia framework. J Adv Prosthodont 2013;5:448-51.

53. Jiang L, Wang CY, Zheng SN, Xue J, Zhou JL, Li W. Effect of $\mathrm{Fe}_{2} \mathrm{O}_{3}$ on optical properties of zirconia dental ceramic. Chin J Dent Res 2015;18:35-40.

54. Spyropoulou P-E, Giroux EC, Razzoog ME, Duff RE. Translucency of shaded zirconia core material. J Prosthet Dent 2011;105:304-7.

55. Sabet H, Wahsh M, Sherif A, Salah T. Effect of different immersion times and sintering temperatures on translucency of monolithic nanocrystalline zirconia. Futur Dent J 2018;4:84-9.

\author{
Sorumlu Yazarın Yazışma Adresi \\ Adres: Dt. Ceyda Başak INNAL \\ Gazi Üniversitesi Diş Hekimliği Fakültesi \\ Protetik Diş Tedavisi Ana Bilim Dalı, Ankara \\ Bişkek Cd. (8.Cd.) 1.Sk. No:4 06490 \\ Emek - ANKARA \\ e-mail: ceydabasak.inal@gazi.edu.tr
}

